\title{
The Life Center Unit's Design for Inclusive Schools in Turkey: A Case of Gokkusagi Primary School
}

\author{
Simge Gülbahar ${ }^{1}$, Özge Cordan ${ }^{2, *}$ \\ ${ }^{1}$ International Masters of Interior Architectural Design Program, Istanbul Technical University, Taksim, 34437, Istanbul, Turkey \\ ${ }^{2}$ Faculty of Architecture, Istanbul Technical University, Taksim, 34437, Istanbul, Turkey
}

Copyright $\odot 2018$ by authors, all rights reserved. Authors agree that this article remains permanently open access under the terms of the Creative Commons Attribution License 4.0 International License

\begin{abstract}
Human rights assured whole population of equal education opportunity across the world by means of inclusive education, which provides non-discriminated and non-stigmatizing educational environment for the disabled students and their peers. Inclusive education proposes to increase participation and integration of disabled students in educational environments through support spaces. In Turkey, SERÇEV (Children with Cerebral Palsy Association) has encouraged 'life center unit' as a support space at primary level inclusive education school, which is called Gokkusagi Primary School in Ankara. The aim is to support disabled students' relationships with other students and users in the school environment. Establishment of life center unit brings out a fact that there is a spatial necessity for social integration in inclusive education schools, which is open to all population to respond their daily needs, especially for disabled students. According to this purpose, interviews were conducted with parents of students to find out the needs related with the usage of life center unit. In this paper, Gokkusagi Primary School will be taken as an example to find out user's expectations and needs for defining a base related to design criteria of the life center unit. Site visits and, interviews at site visits help define user type, type of use, period of use and spatial requirements of life center unit in inclusive education environments. This study aims to create a base for design criteria of the life center unit in order to utilize for further implementations through universal design principles.
\end{abstract}

Keywords Life Center Unit, Inclusive Education, Universal Design, Accessibility, Usability

\section{Introduction}

After World War II, Universal Declaration of Human Rights (1948), a milestone in maintaining human rights, was declared to provide 'equality' among the entire population in the world. Education that is approved as one of the human rights becomes a need for sustaining equality in the society. Thus, emphasis on right-based approaches has been recently increased [1], so that governments start to develop educational activities given equal opportunity to all students. Education has a significant role in people's lives. Therefore, right-based approach to education contributes noteworthy added value that makes children more confident and creates a positive effect on social integration as well as social justice [1]. UNICEF (2012) states that governments assumed to involve actions in education to fulfill, to respect and to protect the right of education in order to ensure that children with disabilities might realize their rights to education [2].

Special education generates an environment for the people with special educational needs (SEN). Therefore, students' physical diversity makes it compulsory to criticize educational environments in terms of inefficiencies in accessing educational facilities. Inclusive education is a special education method, which brings both disabled and non-disabled students in the same school environment. Moreover, increasing communication between disabled and non-disabled students is an outcome of this method, which lets disabled people being aware of their potential in the societal production.

Inclusive education can be taken to an individual level by generating facilities, which eliminate students' disability conditions, in order to improve their academic and social skills. Supportive educational facilities are an option in inclusive education in terms of rehabilitating and teaching fundamental life skills for students with SEN. Inclusive educational environments should support all students to get social interaction with each other for quality education. Supporting disabled students' communication and interaction with their non-disabled peers creates an empathetic environment that helps disabled students feel themselves self-confident and realize their own potential. In this context, SERÇEV (Children with Cerebral Palsy Association) initiated a "life center unit" as a supportive 
space in an inclusive educational school - Gokkusagi Primary School- in Ankara in Turkey, considering the social and cultural needs. Life center unit fosters a sociable space where all collaborators in the school can improve relationships with each other. Therefore, maximum level of user participation is expected for an effective usage in the school environment. However, it has different types of users having accessibility and usability problems in the usage of life center unit. Accessibility and usability problems arising from diverse disability situations in the life center unit of Ankara Gokkusagi Primary School need to be solved to respond both physical and social expectations for life center unit.

Inclusive education eliminates social problems in education, whereas it brings out spatial problems, which reduce social interaction between disabled students and non-disabled students. Physical and spatial problems must be eliminated in life center unit in order to ensure user participation, thereby the integration of disabled students in education. Physical and social necessities of space for increasing social integration in life center unit of inclusive schools should be necessarily defined to define design principles for further implementation of life center unit.

This paper aims to give a framework that helps to define design criteria of life center unit. The relation between human needs and factors and interior space that suggested in this paper helps to define design criteria of life center unit considering the accessibility and usability problems.

Methodology of the study is based on literature review on universal design and inclusive education, and a case study including site visits and face to face interviews. As students are not eligible to get useful data for using of life center unit, participants of interviews are selected only among the parents of students who are under eighteen years-old and some of whom have mental retardations. Literature review helps to give a framework about inclusion in Turkish education system and its educational requirements. Moreover, the concurrence between inclusive education and universal design reveals why universal design should be used in life center unit's design. Furthermore, life center unit are assessed through a case study, which includes analyses from site visits and interviews with parents of students in Gokkusag1 Primary School. It helps to define current conditions and future expectations of life center unit. Spatial necessities of life center unit are also put forwarded in order to define design criteria of life center unit.

\section{Inclusive Education in Turkey}

Education is one of the fundamental human rights that should be provided by countries to their citizens. 'Education for All' movement encourages countries to remove the discrimination against people who have different learning abilities in the society [3]. Inclusive education emerges as a method of special education that gives individualization opportunity in education based on the special educational needs of people. This method promotes accessibility in education for disabled people who have special educational needs, while removing communication barriers with non-disabled people [4]. UNESCO (2015) defines inclusive education as "a process of addressing and responding to the diversity of needs of all learners through increasing participation in learning, cultures and communities, and reducing exclusion within and from education" [4]. Furthermore, according to UNESCO (2009), inclusive education encompasses "changes and modifications in content, approaches, structures and strategies, with a common vision, which covers all children of the appropriate age range and a conviction that it is the responsibility of the state to educate all children" [3].

In Turkey, inclusive education was mentioned at first in 1983 in 'Law on Children with Special Needs' in order to suggest that disabled students could be in same classroom with their peers in mainstream schools [5]. In addition, Article 4 of 'The Ministry of National Education-Regulation on Special Education Institutions' published in 2012 states that the aim of special education is providing disabled people education rights according to their abilities and interests, making disabled people more compatible and productive through student-centered approach to teach fundamental life skills [6]. Separate classes for students with disabilities create a discriminative education environment, which leads to reduction in empathy in society. Thus, inclusive education has become important in this era to integrate mainstream educational curriculum among countries.

Durak (2010) regards about inclusive education that collaborators such as families, teachers, and communities should join in the process of educational activities [7]. Family education is also mentioned in legislations [6], and it shows that families are a part of inclusive education. Furthermore, inclusive education is a lifelong educational activity which is supported by other collaborators. Hence, it contributes to the rehabilitation of disabled people in the society by removing barriers.

Durak (2010) summarizes the principles of inclusive education according to Turkish legislations that are based on process-based and student-centered understandings of inclusion as follows:

a Choosing the most appropriate education environment for children with SEN,

b Organizational adaptations in the education environments,

c Individualized Education Programme (IEP)

d Collaborative team study

e School-centered supportive services

$\mathrm{f}$ Adaptations in the physical education environment [7].

Flexibility of curriculum in inclusive education contains 
adaptations according to special educational needs. 'Individualized Educational Program' (IEP) concerns all students' learning activity considering their individual needs. It has student-centered concerns which provide students with SEN to improve life skills according to both social and academic needs. Supportive educational services maintain student-centered approach in inclusive education as they contribute to the academic and social rehabilitation of students with SEN. Although legislations and regulations in Turkey explain supportive services, missing information about spatial necessities of these services cause design failures in space usage.

\section{Accessibility and Usability in Universal Design and Their Relation with Inclusive Education}

Environmental conditions affect human's quality of life, which depends on responding to basic human needs. Queries about person-environment relationship must add a legislative process of design to maintain human rights in daily life practices. In that case, accessibility and usability should consider solving design problems to bring equality in space usage with sustainable solutions.

\subsection{Accessibility and Usability in Universal Design}

Accessibility and usability are the two comparable concepts that are based on the person-environment relationship. Accessibility mainly concerns users' apprehension about the activities that they need to reach independently. Usability and accessibility analyze human functioning and environmental obstacles separately to gather information about potential activity failure. Accessibility is a phenomenon about arranging physical environment according to user requirements. At that point, individualization related to space usage should be considered a critical issue in accessibility and usability of physical environment. These approaches show that usability is based on the satisfaction of functional requirements, efficiency of user performance in particular environment. Hacihasanoglu (2003) simply regards that "accessibility is a term that all individuals may reach and access everywhere, usability is a term that all users may use a product or equipment; so that, designers must consider accessibility and usability together." [8]. Iwarson and Stahl (2003) summarize the literature that accessibility is based on analyses of personal and environmental components together to define accessibility problems; usability includes activity components, also analyses of personal, environmental, and activity components together to define usability problems [9]. In other words, accessibility gives a definition about the proficiencies of an environment according to legal dimension, while usability is a user satisfaction that is provided by product or environment.

Considerations on physical environment in terms of accessibility and usability develop different approaches for design process in order to bring social justice in spatial context. Diversity of users intend to create a discriminative space in terms of utilizing facilities. Design of a space needs an integrative approach to response to user's demands by solving accessibility and usability issue. Universal design becomes an approach that maintains equality principle of human rights. Universal design puts an emphasis on maintaining accessibility and usability of the physical space, which is contrary to special adaptations for disabled people's needs.

Universal design helps articulation of bodily differences to physical environment, thereby a spatial solution for disability issue. "World Health Organization" (WHO) interprets the disability definition as an umbrella term as "impairments, activity limitations and participation restrictions, referring to the negative aspects of the interaction between an individual and that individual's contextual factors" [10]. Moreover, disability refers to a physical competence of a user to meet functional requirements of the environment. Universal design approach offers a negotiation between user demands and environment to maintain full inclusion by removing barriers. Goldsmith (2000) states that universal design extends common parameters of design while it minimizes special regulations in space according to disabled people's demands [11].

Problems of human functioning in space are usually discussed by accessibility and usability concepts in case that disabled people dominate in the user group. Universal design principles solve spatial problems without exception in user type, as they consider disability as a human-functioning problem (Table 1). In addition, universal design principles help design process tolerate the spatial failures in the future. Problems of accessibility and usability can be eliminated to provide a non-discriminatory environment for people during space usage with universal design principles.

\subsection{Relation between Inclusive Education and Universal Design}

Inclusive education contributes to the social participation by gathering diversities in the same educational environment. It admits that each student has their own potential, and this potential needs to be brought out for increasing corporation and unity in society. This is an advantage for students with SEN to feel themselves part of the society.

Participation of other contributors, such as families, teachers and communities, causes diverse user's demands to be considered. Diverse user types in inclusive education environment include complex user demands, and thus human functioning in space becomes a major issue. Moreover, different abilities of students in an inclusive environment pointed out the question whether efficient use should be ensured to them in there. 
Table 1. The Principles of Universal Design (Copyright 1997 NC State University, The Center for Universal Design) [12]

\begin{tabular}{|c|c|}
\hline 1- Equitable Use: & The design is useful and marketable to people with diverse abilities. \\
\hline 2- Flexibility in Use: & The design accommodates a wide range of individual preferences and abilities. \\
\hline 3- Simple and Intuitive Use & $\begin{array}{l}\text { Use of the design is easy to understand, regardless of the user's experience, } \\
\text { knowledge, language of skills, or current concentration level. }\end{array}$ \\
\hline 4- Perceptible Information: & $\begin{array}{l}\text { The design communicates necessary information effectively to the user, regardless } \\
\text { of ambient conditions or the user's sensory abilities. }\end{array}$ \\
\hline 5- Tolerance for Error: & $\begin{array}{l}\text { The design minimizes hazards and the adverse consequences of accidental or } \\
\text { unintended actions. }\end{array}$ \\
\hline 6- Low Physical Effort: & The design can be used efficiently and comfortably and with a minimum of fatigue. \\
\hline 7- Size and Space for Approach and Use: & $\begin{array}{l}\text { Appropriate size and space is provided for approach, reach, manipulation, and use } \\
\text { regardless of user's body size, posture, or mobility. }\end{array}$ \\
\hline
\end{tabular}

Universal design gathers all differences in the same environmental conditions without exception. Disabilities of students can be solved by using universal design principles for designing inclusive education environments. Durak (2010) states that universal design promises social integration, participation and equity of all people including people with disabilities due to accessibility and usability that accompany until the end of design process [7]. This feature of universal design is eligible to carry out the inquiries of inclusive education environment.

\section{4. 'Life Center Unit' As a Need for Inclusive Education Environment}

Support spaces in inclusive education are utilities, which maintain special educational needs in inclusive education environment. Although there was not an explicit definition for its design in legislations, life center unit was appeared as a support space in inclusive educational environments. In this chapter, current situation of life center unit as a support and social space is criticized to make assessments related to design problems in the life center unit.

\subsection{An Analysis of the Life Center Unit in Ankara Gokkusagı Primary School}

SERÇEV (Children with Cerebral Palsy Association) determined Ankara Gokkusagi Primary School in Turkey as the first inclusive school, which considers inclusive educational requirements in design process. Gokkusag1 Primary School includes both general classrooms and special education classrooms. General classrooms consist of students with SEN and their peers, while special education classrooms only consist of students with SEN and mental retardations. In Gokkusagı Primary School,
SEN include students with cerebral palsy (CP) too. Cerebral Palsy is a term Umbrella term for motor impairments caused by brain damages at birth or early development of human being. Therefore, physical abilities of students in the school cannot be restricted. It indicates a wide range of possibilities in terms of person-environment interaction. Most of students with cerebral palsy use assistive equipment; for this reason, spatial organization considers such equipment as a part of user ability. Bodily capability of students with $\mathrm{CP}$ can also differ according to severity of brain damage. Diversity of bodily capability of students with CP indicates that spatial consideration of the spaces where they participate should evolve around the idea of effective use and full participation.

In the scope of this study, first visit was made to Gokkusag1 Primary School to analyze the spatial use of the school through interviews and site visits in 2015. The school has two wings that one of the wings has general classrooms, and the other one has special classrooms and resource rooms. In time span, some spatial adjustments were made due to the emerging necessities in usage. One of the adjustments was adding the life center unit as a support space (Fig. 1) to the spatial organization of the school. First idea about establishment of the life center unit is a support space for students with SEN in order to improve their basic life skills. Considering the students with SEN, this unit has failures of spatial organization, which are unidentifiable in terms of functioning and human activities. Moreover, the location of the life center unit in the building is on the same floor with special education classrooms, which seems suitable regarding its use. Spatial ambiguities are dominant in the space and cause accessibility and usability problems. In addition, spatial requirements are not definable to handle spatial failures that cause usage errors. 


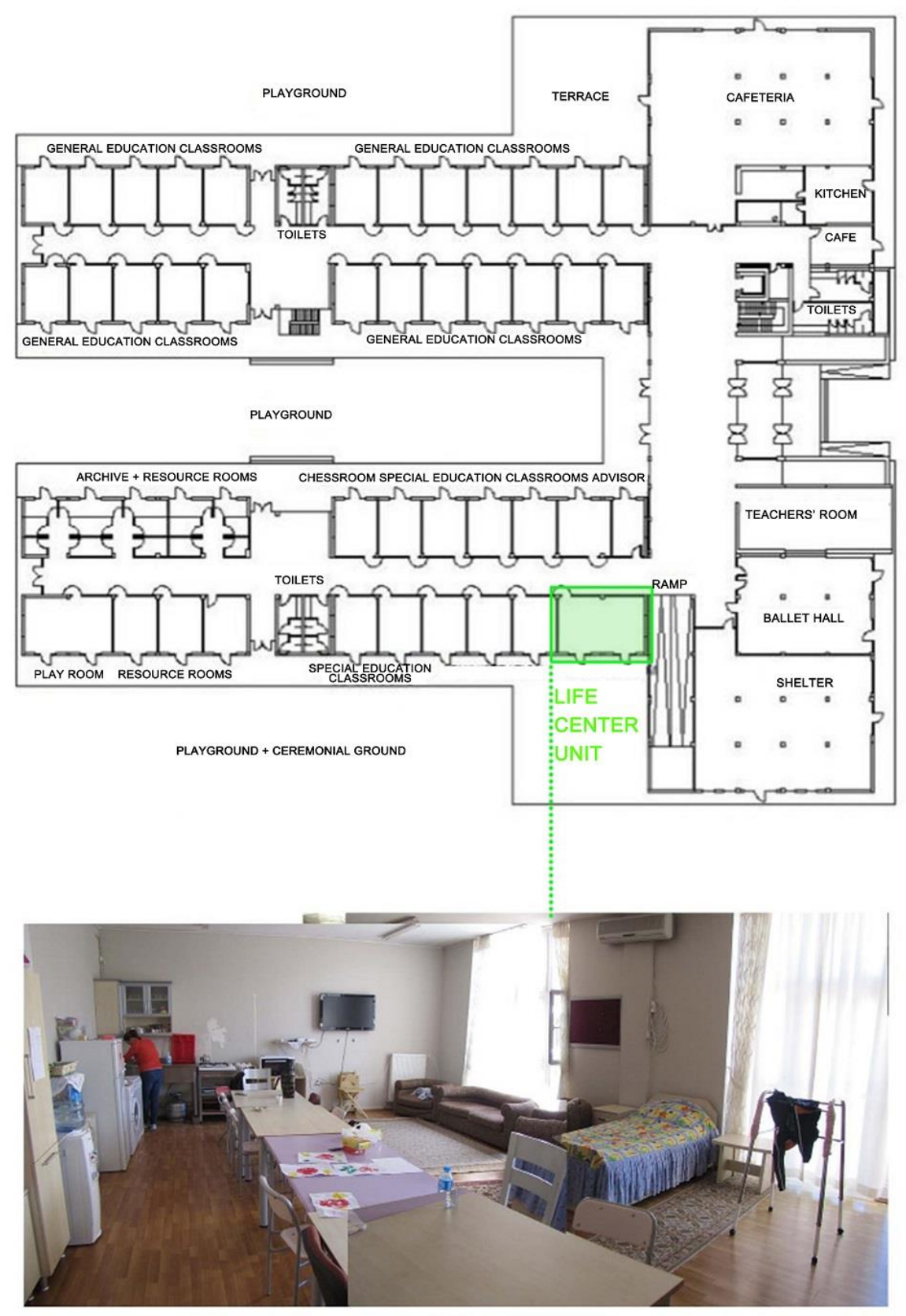

Figure 1. Ground floor plan of Gokkusagı Prımary School [7] and the life center unit in 2015 (Simge Gülbahar's personal archive)

Second visit to the life center unit in Ankara Gokkusagi Primary School was in 2017 (Fig. 2). It was observed that the life center unit turned into a flat. It had basic house equipment same as the previous one but they were not eligible for use efficiently by all collaborators of the life center unit. Although spatial functions in the life center unit were more definable then before, territorial problems between functions continued when they were compared with the previous version of it. The expectations about life center unit are creating a social space where students with SEN can learn and practice fundamental life skills. Uncertainties about the usage of life center unit continue precluding the productivity of all participants in there. During the second site visit, interviews have been done with the parents of the students. Interviews encompass the questions that help to understand how participants of life center unit use this place. Answers introduce some information about use of life center unit from the view of participants in terms of frequency of use, reasons of use, and failures in use. Furthermore, necessity of life center unit is affirmed by the answers as life center unit constructively affects students with SEN.

According to first visit of the Gokkusagi Primary School, spatial requirements of the life center unit have uncertainties to maintain quality in an inclusive education environment. At the second visit of the Gokkusag1 Primary School, interviews were conducted with parents of students both students with SEN and without SEN) to find out the 
purpose of life center unit in addition to the previous personal interviews at site visits. They show that parents are satisfied with the outcomes of the opportunities that the life center unit offers their children. In addition, facilities of the life center unit are resourceful for students to increase their academic and social skills. However, users of life center unit cannot use this space effectively related to varieties of their physical compatibility. Students with SEN need an accompanying person who helps them due to their bodily incapability. For this reason, other contributors are taken into account to define user type for the life center unit design.

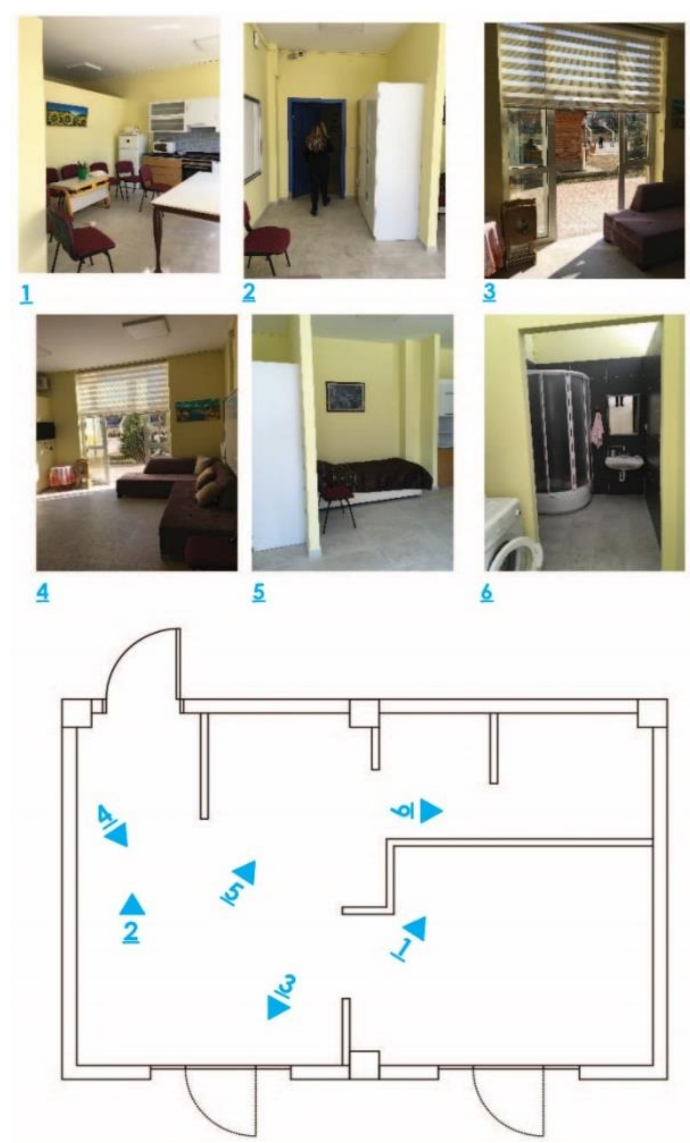

Figure 2. The life center unit in Gokkusagı Prımary School in 2017 (Simge Gülbahar's personal archive)

\subsection{Assessments of Life Center Unit's Use and Defining its Design Criteria}

Life center unit is a significant development in inclusive education environment in Turkey. Curriculum of inclusive education aims to give flexible educational facilities that can be adapted to special educational needs, and it also affects spatial needs. Thus, design process of life center unit needs to include adaptable solutions regarding functional requirements. Spatial solutions should encompass all users in life center unit by responding to their demands.

Life center unit can contribute to social responsibility of inclusive education to welcome all students in the school.
Home experiences for student with SEN are helpful to improve their basic life skills, but this unit should provide the needs, considering purpose of inclusive education.

In this sense, expectations about usage of life center unit can be categorized as below;

1. User type: students with/without SEN, teachers, advisors, therapists, other staff, parents, caretakers, local community, visitors and students with SEN from outside

2. Type of use: curriculum-based use, collaborative use, community-based use

3. Period of use: during school hours, out of school hours

4. Spatial requirement: formal learning spaces, informal learning spaces, non-specialist spaces, family waiting room, meeting and training activities, personal care spaces, easily controllable, specialized or multipurpose spaces used after school hours with separate entrance.

Life center unit has both academic and social rehabilitation purpose, in addition to its educational responsibilities. Flexible educational curriculum allows the concept of life center unit to have multi-purpose activities. Then multi-functional purpose needs meticulous spatial organization of life center unit, which would allow users to independently benefit from the space.

Life center unit is based on the idea of promoting basic life skills of student with SEN. In one hand, home experience is expected to response to this idea, on the other hand the approach should avoid creating home-type of environment. The spatial organization of life center unit allows increasing social participation among all students. Students with SEN should have an area that also maintains their individual needs.

According to analysis of the life center unit in Gokkusagi Primary School, the opportunities that are provided by the life center unit are in progress. Interviews with parents show that spatial expectations about the life center unit indicate a broaden concept comparing the observations in the life center unit of Ankara Gokkusagı Primary School. According to the assumptions made in the life center unit in Ankara Gokkusagı Primary School, the design criteria must be integrated into the design process of life center unit in order to prevent spatial impediments because of its multifunctional purpose. Universal design is user-centered approach in design process to respond to user needs in an environment equally. In this sense, 'universal design principles' are a key strategy to absorb human needs and factors in order to provide spatial requirements (Fig. 3). Interior space and universal design principles are settled in a matrix system while defining design criteria of the life center unit. This matrix would help decide conceptual and constructional needs of a life center unit design. In addition, this matrix can be adaptable according to future needs, aspirations and demands of life center unit for all collaborators. 


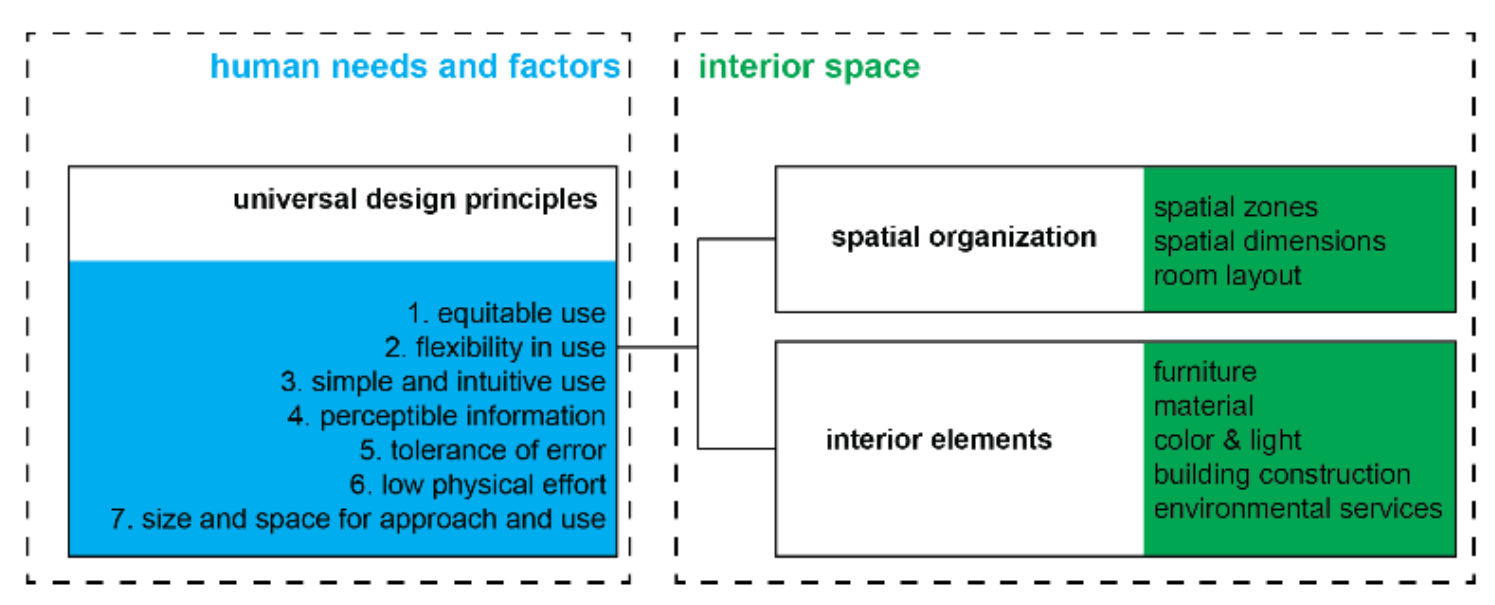

Figure 3. The relation between human needs and factors and interior space (Simge Gülbahar's personal archive)

\section{Conclusions}

Inclusive education helps the integration of students with SEN in society without any discrimination in education environment. According to investigations about life center unit of Gokkusagi Primary School, life center unit has been established to provide educational support to students with SEN. However, expectations for life center unit show that all students and participants of inclusive education want to be gathered to remove discriminative trait of the current life center unit. Inclusive education encompasses stakeholders at every step to be successful [2]. For this reason, inclusive education must welcome all users in the school to contribute to educational practice, though life center unit primarily aims to teach basic life skills to students with SEN. Thus, this unit must foster participation of other collaborators in inclusive education such as local communities, parents as well as students.

Definition of life center unit is ambiguous, so it creates a complexity to manage an effective design process. Therefore, life center unit must be added as a support space in legislations and regulation in Turkey for social and academic rehabilitation of students with SEN. It may bring a definition to the life center unit while saving it from home-type approaches for its design. Moreover, specifying design criteria of life center unit is necessary to provide equal and quality educational opportunity considering the purpose of the inclusive education. Full participation to educational activities is expected in inclusive education to minimize spatial problems.

Legislations and regulations about inclusive education in Turkey do not include any enough information about life center unit as a support and social space to help the development of life center unit's design standard. Design standards for educational building should include life center unit, and the gap between theory and practice may recover in the further implementation of life center unit. Life center unit is not a flat; but it can simulate the functions of a home environment for educational purposes. Inclusive education concerns full participation all students in education without any identification. Universal design considers reaching wide-range of users for usability of a product. Both universal design and inclusive education indicate equality and integrity in a related subject. Universal design may solve the spatial problems because of user diversity that brings out the problems about human functionality in life center unit. Universal design principles completely respond to human needs and factors, so it helps build an inclusive educational environment effectively.

Design criteria for life center unit must be specified regarding the relations suggested in Fig. 3. Thus, spatial failures in life center unit are reduced with the help of design criteria. In this context, this paper introduces the assessments of life center unit to specify its design criteria for future implementations. So, universal design principles help designers supply a productive design process for life center unit's design.

\section{Acknowledgements}

We are very grateful to SERÇEV (Children with Cerebral Palsy Association) for their collaboration and contribution to this study.

This work was supported by Research Fund of Istanbul Technical University. Project Number: 39791

\section{REFERENCES}

[1] United Nations Children's Fund (UNICEF) (2007). A Human Rights-Based Approach to Education for All. Retrieved March, 2018 from

http://unesdoc.unesco.org/images/0015/001548/154861e.p df.

[2] United Nations Children's Fund (UNICEF) (2012). The Right of Children with Disabilities to Education: A Rights-Based Approach to Inclusive Education. Geneva. Retrieved March 2018 from 
https://www.unicef.org/disabilities/files/UNICEF_Right_t o_Education_Children_Disabilities_En_Web.pdf.

[3] United Nations Educational, Scientific and Cultural Organization (UNESCO) (2009). Policy Guidelines on Inclusion in Education. France: UNESCO. Retrieved April, 2016

http://unesdoc.unesco.org/images/0017/001778/177849e.p df

[4] United Nations Educational, Scientific and Cultural Organization (UNESCO) (2015). Teaching Children with Disabilities in Inclusive Settings. Paris: UNESCO and UNESCO Bangkok Office. Retrieved April, 2016 from http://unesdoc.unesco.org/images/0018/001829/182975e.p df.

[5] Sucuoğlu, B. (2004). Türkiye'de Kaynaștırma Uygulamaları: Yayınlar/Araştırmalar (1980-2005). Özel Eğitim Dergisi, 5 (2), 15-23.

[6] Milli Eğitim Bakanlığı Özel Eğitim Kurumları Yönetmeliği, Resmi Gazete, 18 Mayıs 2012, say1 28296.

[7] Durak, S. (2010). Searching for a common framework for education and architecture through reconsideration of universal design principles for promoting inclusive education in primary schools ( $\mathrm{PhD}$ thesis). Middle East Technical University, Graduate School of Natural and Applied Science, Ankara.

[8] Hacihasanoğlu, I. (2003). Universal Design=Evrensel Tasarım, Tasarım + Kuram, (3), 93.

[9] Iwarsson, S. and Stahl, A. (2003) Accessibility, usability and universal design-positioning and definition of concepts describing person-environment relationship, Disability and Rehabilitation, 25:2,57-66.

[10] WHO (2011), World Report On Disability, WHO Press, Retrieved from http://www.who.int/disabilities/world_report/2011/report.p df

[11] Goldsmith, S (2000), Universal Design, Architectural Press.

[12] The Center for Universal Design (CUD) (2008). The Principles of Universal Design. North Caroline State University: The Center for Universal Design. Retrieved 28 February, 2018, from https://projects.ncsu.edu/ncsu/design/cud/about_ud/udprin ciplestext.htm. 